\title{
ERRATUM
}

T. A. M. Teunissen - W. J. H. M. van den Bosch

H. J. M. van den Hoogen · A. L. M. Lagro-Janssen

\section{Prevalence of urinary, fecal and double incontinence in the elderly living at home}

Published online: 13 January 2004

(C) International Urogynecological Association 2004

Int Urogynecol J (2003) DOI 10.1007/s00192-003-1106-8

When this contribution was published, the authors were given in the wrong order and the e-mail address was incorrect. The proper order and correct e-mail address are now given above.

The online version of the original article can be found at http:// dx.doi.org/10.1007/s00192-003-1106-8

T. A. M. Teunissen $(\varangle) \cdot$ W. J. H. M. van den Bosch

H. J. M. van den Hoogen - A. L. M. Lagro-Janssen

Department of General Practice and Social Medicine,

University of Nijmegen, HSV 229, Postbus 9101,

6500 HB Nijmegen, The Netherlands

E-mail: T.Teunissen@HAG.umcn.nl 